\title{
Correction to: Energy Retrofit of Existing Building Stock in Amman: State of the Art, Obstacles and Opportunities
}

Sameh Shamout, Paola Boarin, and Alessandro Melis

\section{Correction to: \\ Chapter "Energy Retrofit of Existing Building Stock in Amman: State of the Art, Obstacles and Opportunities" in: C. Alalouch et al. (eds.), Advanced Studies in Energy Efficiency and Built Environment for Developing Countries, Advances in Science, Technology \& Innovation, https://doi.org/10.1007/978-3-030-10856-4_14}

The original version of this chapter "Energy Retrofit of Existing Building Stock in Amman: State of the Art, Obstacles and Opportunities" was inadvertently published with incorrect affiliation of Dr. Paola Boarin. The correct affiliation "School of Architecture and Planning, Faculty of Creative Arts and Industries (CAI), University of Auckland, Auckland, New Zealand" has been corrected in the chapter. 